\section{Chambers's Technical Dictionary}

Comprising Terms used in Pure and Applied Science, Medicine, the Chief Manufacturing Industries, Engineering, Construction, the Mechanic Trades. Edited by C. F. Tweney and Dr. L. E. C. Hughes. Pp. viii +960 . (London and Edinburgh: W. and $\mathbf{R}$. Chambers, Ltd., 1940.) 15s. net.

A $\mathrm{N}$ accurate and reasonably comprehensive A technical dictionary has become an almost indispensable adjunct to the equipment of the scientific worker, and also to that of the layman who desires to march with the times. The prodigious growth of knowledge in the natural sciences and their applications has, moreover, necessitated the coinage of a multitude of new words, and if a majority of these can be found, alongside the old ones, within the limits of a single volume, much time is saved and efficiency gained. No single technical dictionary can aspire to completeness, but every good one should include the essential words and expressions, and be available at moderate cost.

Judged by the above criteria, "Chambers's Technical Dictionary" comes out very well indeed. It contains an extraordinary amount of condensed information, which, so far as the writer is competent to judge, is both reliable and up to date. Brevity is naturally its soul, and should the specialist complain that excessive condensation must entail slight inaccuracies, his remedy is to consult an encyclopædia and not a dictionary. A minor criticism can be advanced against what appears to be arbitrary classification, for many of the words included in one or other of the 124 categories which the authors have adopted might equally well have been placed in another. Thus there does not seem any special reason why words like 'adsorption', 'aerosol', 'molecule', and 'osmotic pressure' should be termed 'chemical' rather than 'physical', ; but classifications are always fallible, and like speculative hypotheses, must be scrapped when they are out of date. Among the few omissions noted is the word 'chemotherapy', and agricultural terms in general, though a number of these occur under 'botany'. On the other hand, the inclusion of a large number of medical terms comes as a welcome surprise.

The success of this book is due to the excellent work of a large team of scientific contributors (whose names are not, for the most part, well known), and to the judgment of the two editors; to them for their ability, and to the publishers for their enterprise, the thanks of the scientific and technical world will be readily given.

E. H. T.

\section{Volumetric and Phase Behavior of Hydrocarbons}

By Prof. Bruce H. Sage and Prof. William N. Lacey. (Associated with Research Project 37 of the American Petroleum Institute.) Pp. xii +299. (Stanford University, Calif.: Stanford University Press ; London: Oxford University Press, 1939.) 28s. net. 7 HIS book is mainly concerned with physicochemical principles affecting petroleum technology. It begins with some mathematical and thermodynamic principles, then deals with one, two, and multi-component systems largely from the experi- mental point of view, the text being illustrated by many clear diagrams. There are references to recent literature. The phase rule and thermodynamics are really the basis of the treatment, but the correlation of experimental data is what is emphasized throughout. When quantitative knowledge of the physicochemical properties is available it is introduced. The section on multi-component systems should be particularly interesting to the petroleum specialist. An appendix deals with retrograde condensation.

The book is a courageous and successful attempt to introduce the principles of chemical thermodynamics into a region of technical application where they can be of real importance and significance. In recent years much work has been done on the physico-chemical properties of the individual hydrocarbons, and a book of this character will help in pointing out its significance to the technologist.

\section{Chiltern Country}

By H. J. Massingham. (The Face of Britain Series.) Pp. viii $+120+66$ plates. (London : B. T. Batsford, Ltd., 1940.) 8s. 6d. net.

\section{English Lakeland}

By Doreen Wallace. (The Face of Britain Series.) Pp. viii $+120+66$ plates. (London : B. T. Batsford, Ltd., 1940.) 8s. 6d. net.

7 HESE books are the latest additions to the volumes in the series entitled "The Face of Britain". Numerous photographs of the two districts dealt with have been collected, and excellently reproduced. If selection be the criterion of art, almost every one of these photographs is a work of art, for they show both the diligence and the good taste needed for rightly directing the camera, the wide angle of which makes it difficult to exclude inharmonious objects.

Mr. Massingham describes the Chiltern country with a wealth of detail, both in relation to natural features and rural industries (such as chair-making and "bodger" work), which still, fortunately, survive in the beech wood districts. Attractive comments are made on rural architecture, as, for example, in describing the outside chimney of the cottage "reaching its brick stack up from tiled shoulders".

The first chapter of Doreen Wallace's volume on "English Lakeland" is appropriately entitled "Tourists' Paradise". The author writes with more intimate knowledge than that of a tourist, having been born and brought up in the district. The wellinformed account of sheep farming on the fells provides a true picture of the relation of life and landscape which is such an important element in the æsthetics of scenery.

With reference to the opinions of the author on the appreciation of Lakeland scenery, there is one point in which we feel bound to record disagreement. We are told, p. 11, that "Wordsworth had the woolly mind of the truly good". His "Guide Through the English Lakes", so far from being evidence of a "woolly mind", is one of the clearest and most accurate analyses of natural scenery that has ever been written. 